\title{
PERSPECTIVAS, ITINERARIOS E INTERSECCIONES: EXPERIENCIAS Y PROPUESTAS DE APROPIACIÓN CULTURAL DE MARROQUÍES BAJOS (JAÉN)
}

\author{
PERSPECTIVES, ITINERARIES AND CONVERGENCES: PRACTICE AND PROPOSALS \\ OF THE CULTURAL APPROPRIATION OF MARROQUIEES BAJOS (JAÉN)
}

FRANCISCA HORNOS MATA (*)

NARCISO ZAFRA DE LA TORRE (*)

MARCELO CASTRO LÓPEZ (*)

"Lo que resiste puede sobrevivir sólo en la medida que se integra"

M. Horkheimer y Th. W. Adorno, Dialéctica de la Ilustración, 1999: 194.

\section{RESUMEN}

Se viene aplicando desde 1995 una normativa de protección sobre la zona arqueológica de Marroquíes Bajos, situada en el área de crecimiento de la ciudad de Jaén, que obliga a la realización de excavaciones arqueológicas antes de edificar. La conservación de algunos espacios y construcciones de interés ha requerido la modificación de proyectos de obra e incluso del planeamiento urbano, y ahora se plantea la necesidad de acondicionar estos sitios para la visita pública. Esta conservación arqueológica persigue mejorar la calidad urbana de este borde de la ciudad, considerando el aprovechamiento estrictamente turístico como un fenómeno tangencial a este propósito.

\begin{abstract}
Since 1995 we have applied protection regulations for the archaeological area of Marroquies Bajos, located in the expanding area of the city of Jaén. These regulations force us to make archaeological excavations before building takes place. The preservation of some spaces and constructions of interest has called for the modification of building projects and even of the town planning, and now it is necessary to make these places suitable for public visits. This
\end{abstract}

(*) Delegación Provincial de Cultura. Martínez Montañés 8. 23007 Jaén. Correo electrónico: fhm@ @etemail.es.

El artículo fue remitido en su versión final el 10-X-2000. archaeological conservation aims to improve the urban quality on this side of the town, while exploitation for tourism is only marginal activity.

Palabras clave: Patrimonio Arqueológico. Arqueología Urbana.AltaAndalucía. Paisaje Agrario. Sitios Arqueológicos y Público.

Key words: Archaeological Heritage. UrbanArchaelogy. Upper Andalusia. Agrarian Landscape. Archaeological Sites and Public.

\section{INTRODUCCIÓN}

Esta contribución tiene el propósito de presentar una primera reflexión acerca de la zona arqueológica de Marroquíes Bajos (en adelante Z.A.M.B.) como sitio musealizable, susceptible de acoger la visita del público después de cinco años de aplicación de una normativa de protección motivada por la urbanización del sector norte de la ciudad de Jaén (Figs. 1 y 2), que ha permitido el desarrollo de extensas excavaciones antes de la edificación. Esta normativa ha amparado varias decisiones de conservación, que afectan a espacios y elementos inmuebles aparecidos en distintos lugares de la zona arqueológica (Fig. 3).

En este momento no se pueden presentar realidades acerca de la musealización de la Z.A.M.B., ni por supuesto evaluar las respuestas del público. 


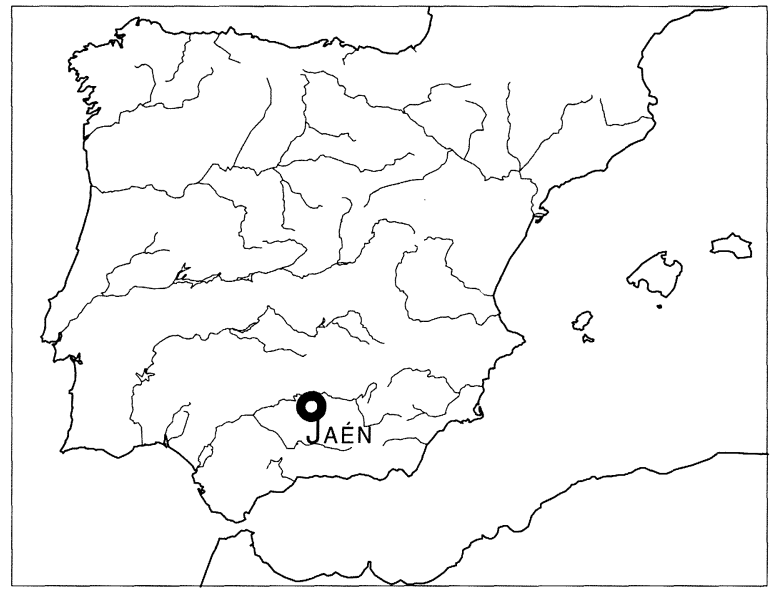

Fig. 1. Localización de la zona arqueológica de Marroquíes Bajos en la Península Ibérica.

Sin embargo, la experiencia de Marroquíes Bajos tiene un indudable interés, aunque sólo sea por la peculiaridad de este sitio, donde concurren circunstancias claramente diferentes a aquellas que observamos en la mayoría de las zonas arqueológicas musealizadas en nuestro país. Un parque arqueológico suele ser una zona delimitada y cerrada, generalmente situada en un ámbito rural, donde se concentran vestigios arqueológicos de periodos concretos que tienen un valor desmostrado por su excepcionalidad, monumentalidad y/o proyección científica, y casi siempre objeto de una gestión unitaria. Por el contrario, la Z.A.M.B. que pretendemos convertir en un parque arqueológico, contiene las huellas de un paisaje agrario modelado durante más de cinco mil años, dispersas en un ámbito urbano de nueva planta especialmente denso, donde la calidad monumental constituye una excepción, y además carece de una institución específica de gestión. En relación con este último aspecto, se debe subrayar que las funciones de protección, conservación y difusión de la Z.A.M.B. se encuentran radicadas en la Delegación Provincial de Cultura, atendidas por tanto con los mismos medios y recursos destinados a la gestión de varios millares de sitios arqueológicos en todo el territorio provincial. La Z.A.M.B. presenta estas singularidades en el panorama de los sitios musealizados $\mathrm{y}$, sin duda, reune ciertos requisitos comunes a la mayoría de los sitios arqueológicos que nunca alcanzaron un lugar en el camino de la difusión pública.

La primera determinación de la musealización de la Z.A.M.B. se encuentra en la existencia de un

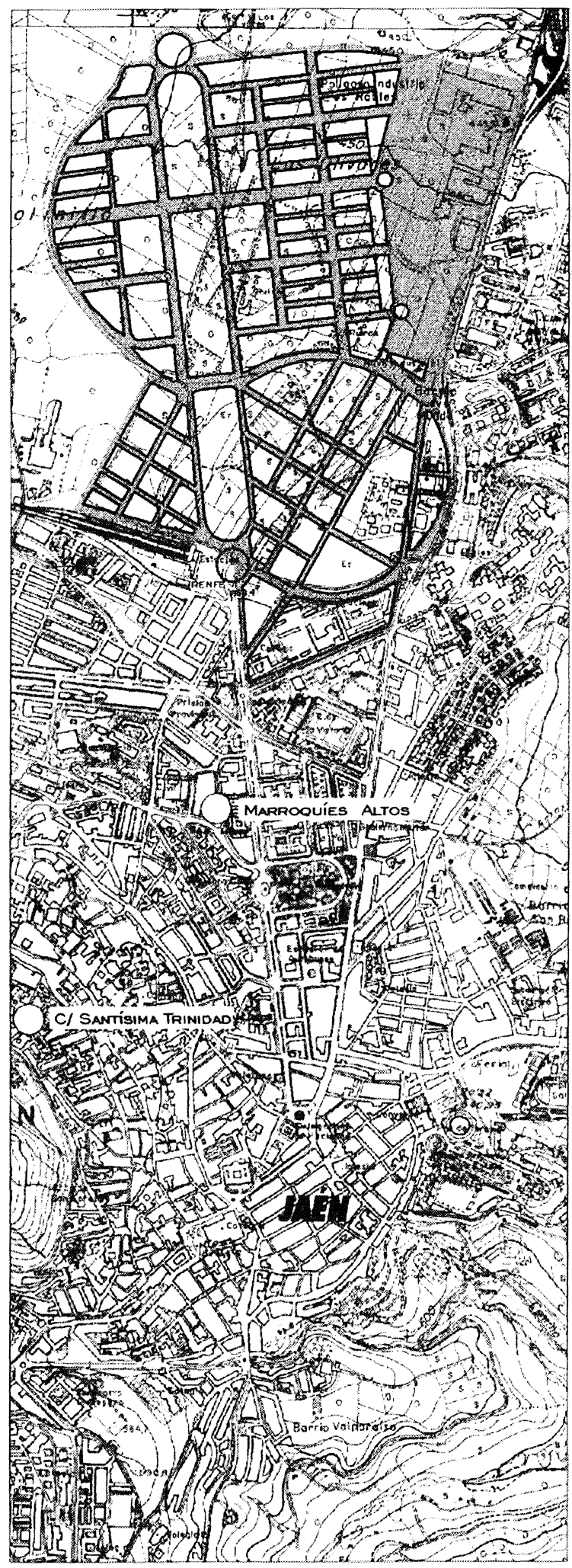

Fig. 2. Delimitación de la zona arqueológica de Marroquíes Bajos (Jaén), escala base 1:10 000 . 


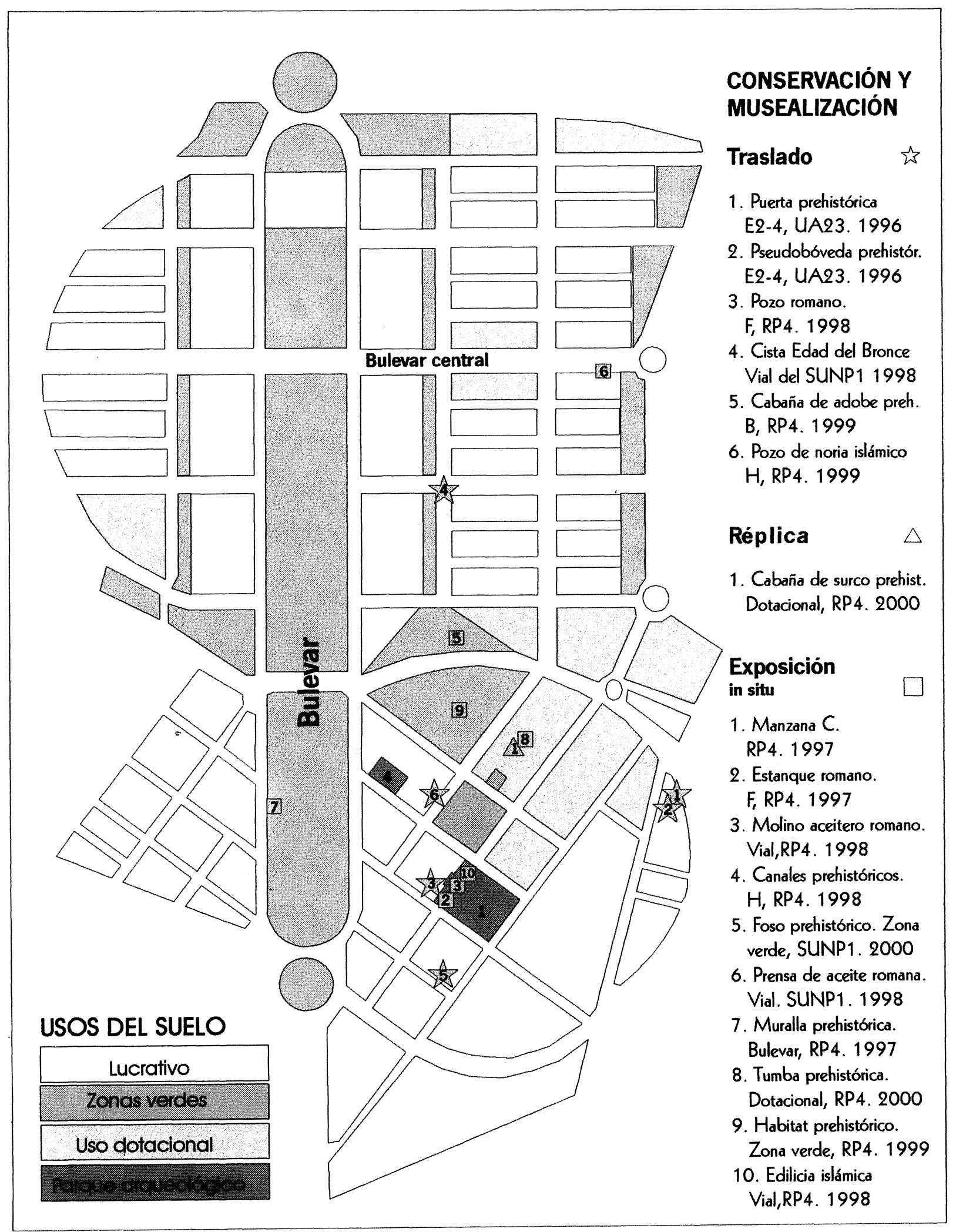

Fig. 3. Decisiones de conservación y musealización en la zona arqueológica de Marroquíes Bajos (Jaén). 


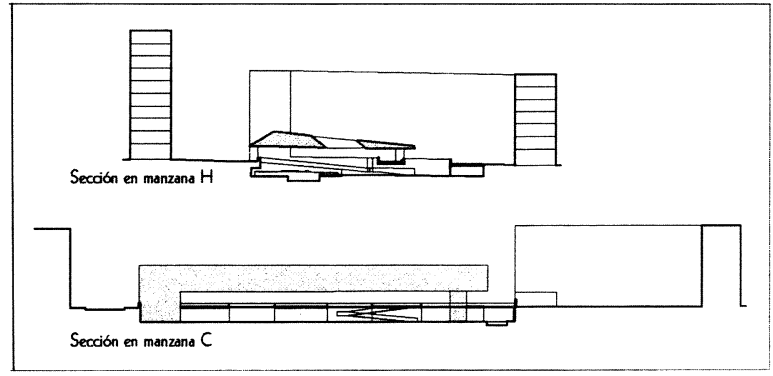

Fig. 4. Secciones representativas del proyecto básico de adecuación funcional de la zona arqueológica de Marroquíes Bajos, Jaén (según Manuel Ibáñez Torrero, arquitecto, y Arturo Ruiz Rodríguez, arqueólogo).

contexto urbano inmediato, un ambiente considerado hostil para la conservación arqueológica que en nuestro caso debe constituir forzosamente el punto de partida del programa de musealización, y por este motivo va a ser objeto de reflexión y análisis en este trabajo. La segunda determinación de la musealización de la Z.A.M.B. procede de las especiales características del proyecto de investigación, desplegado a través de múltiples actividades particulares que sólo están sometidas a condiciones generales de ejecución y a unos criterios mínimos de homogeneidad de la documentación, circunstancia inseparable del sistema de financiación adoptado. La continuidad de las excavaciones ha dependido de la financiación privada desde el momento que los promotores de obras acabaron asumiendo un forzado mecenazgo de la investigación arqueológica, que resultaba inexcusable si pretendían obtener la necesaria autorización administrativa para ejecutar los proyectos de edificación.

Las excavaciones han servido desde luego para recuperar muestras y elementos muebles que entran regularmente en el Museo Provincial, y además han aportado memorias de actividades y documentación de campo depositadas en la Delegación Provincial de Cultura, pero también en varias ocasiones los resultados obtenidos han exigido modificaciones en los proyectos de obra, e incluso la alteración de las previsiones contenidas en el plan de urbanización, para preservar la integridad de determinados espacios y elementos inmuebles (Fig. 3). Estas decisiones de conservación han ampliado notablemente el horizonte del propio documento de catalogación, que en principio sólo contemplaba la conservación integral en las zonas verdes proyectadas en el planeamiento urbano aprobado en la fecha de la incoación del expediente.

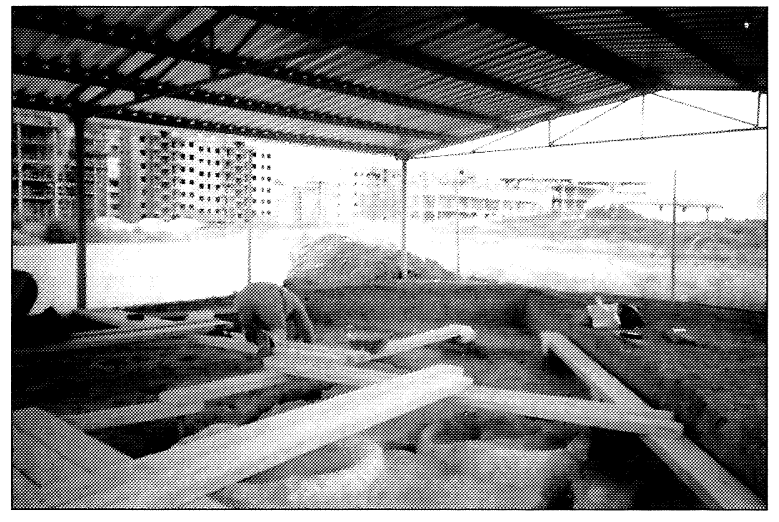

Lám. I. Trabajos de elaboración de molde para réplica de cabaña de surco perimetral, Colegio de la Veracruz, Marroquíes Bajos (Jaén).Archivo de la Delegación Provincial de Cultura.

Asimismo, una decisión relevante para la musealización de la Z.A.M.B. ha sido la redacción durante el pasado año del proyecto básico de adecuación funcional para la visita pública del área central (secciones principales en figura 4), y como continuación de otras actuaciones en materia de conservación acometidas en años anteriores, se debe reseñar también que en fechas recientes se han iniciado los estudios y controles ambientales necesarios para la preservación de algunas construcciones subterráneas mantenidas in situ, y se han obtenido réplicas de otras emergentes que debían ser removidas (Lám. I). Estas últimas iniciativas ponen de manifiesto la necesidad de una reflexión global sobre la musealización de la Z.A.M.B., que debe empezar por evaluar los resultados de las acciones emprendidas hasta ahora, para después establecer las directrices básicas de un programa de actuación en este campo. Este instrumento debe asegurar la coherencia final de los elementos y espacios conservados dentro de un único discurso expositivo, aún reconociendo como limitaciones evidentes que la investigación de la zona arqueológica va a continuar abierta durante bastante tiempo y que el propio objeto de la exposición todavía puede ampliarse a medio plazo.

La preparación de esta contribución ha sido un estímulo en esta tarea, que la discusión se ha encargado de dirigir en múltiples direcciones. No se presenta a continuación el programa de musealización de la Z.A.M.B., sino una información básica sobre la problemática del sitio, seguida de algunos interrogantes acerca del significado de presentar al público los resultados de la investigación arqueológica, y de ciertas implicaciones contenidas en esta 
pretensión. Estas generalizaciones finales tal vez habrían sido innecesarias, si no fuera porque en la presentación de los lugares arqueológicos con frecuencia se ignora que toda exposición siempre encubre una intención y se encuentra inserta en un contexto, en parte plasmado en la conexión establecida entre el sitio y su entorno territorial, y porque casi siempre en esta particular forma de comunicación se presuponen injustificadamente determinados conocimientos que son básicos para lograr una efectiva transmisión de información, relacionados por ejemplo con las disposiciones previas del público, las connotaciones de los recursos expresivos utilizados o la legibilidad de las formas arquitectónicas originales.

\section{MARCO DE ACTUACIÓN}

Aún aceptando que los investigadores están dispuestos siempre a descubrir algo nuevo en un sitio arqueológico, la musealización significa normalmente el agotamiento final del proceso de registro, estudio e interpretación del sitio, realizado a través de un largo periodo de tiempo y, en ocasiones, tal vez enriquecido con las aportaciones de líneas de investigación diferentes. Por el contrario, la Z.A.M.B. conoce desde 1995 un tiempo de descubrimiento permanente, que discurre paralelo al esfuerzo por ordenar y conocer la información para decidir acerca de la conservación. Las circunstancias de la investigación en la Z.A.M.B. han solapado y confundido descubrimiento, conocimiento y conservación en un único tiempo, nuestro tiempo. Las razones de esta situación se encuentran evidentemente fuera del ámbito científico.

La ciudad de Jaén ha experimentado en la segunda mitad de la década de 1990 una rápida expansión hacia el norte (Fig. 2), que se inserta dentro de una coyuntura general de crecimiento del negocio inmobiliario. Así, la extensión delimitada en el P.G.O.U. como suelo urbano consolidado o urbanizable va a representar en los primeros años del próximo siglo la mayor superficie construida que se ha conocido en la historia de la ciudad. La trama urbana unifica sin solución de continuidad tres enclaves que a lo largo del tiempo fueron ocupados de manera selectiva, resultado de diferentes estrategias de localización del asentamiento, como son el Cerro de Santa Catalina, el piedemonte de este promontorio y la planicie septentrional inmediata que conocemos como campiña.
Esta reciente anomalía en la historia de la ciudad hace posible el conocimiento de la Z.A.M.B., y ahora la necesidad de un programa de musealización. La investigación arqueológica convencional, dedicada a ámbitos territoriales menos hostiles, no se había ocupado hasta este momento de Marroquíes Bajos, que empieza a estudiarse precisamente por la necesidad de conocer aquello que va a ser destruido. El volumen de la inversión acaparada por las excavaciones en la Z.A.M.B., desarrolladas de manera ininterrumpida durante los últimos cinco años (1), y en su mayor parte procedente de los agentes públicos y privados que promueven el crecimiento urbano, sólo se explica en la particular coyuntura de este sector económico.

\section{Antecedentes}

La Consejería de Cultura encarga en 1994 la realización de una prospección sistemática en el suelo urbanizable contemplado en el nuevo Plan General de Ordenación Urbana de la ciudad de Jaén (aprobación definitiva con fecha 1997), encaminada a detectar posibles afecciones al patrimonio arqueológico en este ámbito y proponer la introducción en el planeamiento de una normativa específica de protección. Estos trabajos inventariaron y delimitaron bastantes sitios arqueológicos en el entorno de la ciudad, incluyendo algunos dentro de los actuales límites de la Z.A.M.B., pero no consiguieron caracterizar suficientemente la continuidad de las evidencias arqueológicas que los movimientos de tierras de las primeras construcciones demostrarían en algunos de los sectores en vías de urbanización (U.A. n. ${ }^{\circ} 23$ y R.P. n. ${ }^{\circ}$ ).

El siguiente episodio son las paralizaciones de obras en ejecución en los dos sectores indicados con fechas 2 de marzo y 4 de mayo de 1995 (2). La legislación vigente establece un plazo de un mes para el mantenimiento de estas paralizaciones sin responsabilidades para laAdministración (art. 50.2 de la Ley 1/1991, de 3 de julio, de Patrimonio Histórico de Andalucía), tiempo considerado suficiente

(1) El archivo de la Delegación Provincial de Cultura cuenta con el siguiente número de expedientes de actividades de excavación en la Z.A.M.B.: 13 en 1995, 29 en 1996, 40 en 1997, 21 en 1998, 28 en 1999 y 18 hasta julio de 2000.

(2) Se debe destacar que la zona arqueológica fue parcialmente urbanizada antes de 1970 , y también que entonces no trascendió ninguna noticia acerca del interés patrimonial de la misma, cuando debemos suponer que los vestigios tenían la misma entidad descubierta por las actuales excavaciones. 
para conocer la naturaleza de los posibles restos y, en caso necesario, aplicar una figura de protección específica.

\section{Catalogación específica}

Considerando los resultados de las primeras documentaciones y excavaciones urgentes practicadas en el periodo de vigencia de las órdenes de paralización dictadas por la Dirección General de Bienes Culturales de la Junta de Andalucía, y siguiendo uno de los procedimientos establecidos en la Ley 1/1991, de 3 de julio, de Patrimonio Histórico de Andalucía, se decide con fecha 13 de junio de 1995 incoar expediente para la inscripción específica de Marroquíes Bajos como zona arqueológica en el Catálogo General del Patrimonio Histórico de Andalucía (en adelante C.G.P.H.A.). Esta incoación se anuncia a los interesados con fecha 5 de septiembre de 1995 (finalmente publicada en B.O.J.A. de 11 de noviembre) y afecta a una extensión aproximada de 30 ha, correspondientes a los sectores urbanísticos denominados R.P. n. ${ }^{\circ}$ 4, U.A. n. ${ }^{\circ}$ 23, U.A..$^{\circ} 25$ y otros inmediatos. El procedimiento de inscripción en el C.G.P.H.A. se resuelve con fecha 7 de julio de 1997 (B.O.J.A. de 16 de agosto), introduciendo como novedad la incorporación a la zona arqueológica catalogada del sector denominado Suelo Urbanizable No Programado n. ${ }^{\circ} 1$ (S.U.N.P. n. ${ }^{\circ}$ 1), que en el transcurso de la tramitación había dispuesto de un nuevo proyecto de urbanización, hasta alcanzar una extensión final de 129'29 ha.

La legislación andaluza contempla la redacción de unas instrucciones particulares para aquellos bienes afectados por una inscripción específica en el C.G.P.H.A., aplicables desde el mismo momento de la incoación del expediente, que regulan la protección, conservación, investigación, difusión, etc. del mismo, y se superponen al ordenamiento urbanístico vigente. El texto de la inscripción recoge insistentemente la necesidad de una planificación global de la intervención pública en la zona arqueológica, pero remite el procedimiento de autorización de obras a la resolución de cada uno de los expedientes particulares sometidos a licencia municipal, que en la práctica hace inviable la adopción de medidas generales de protección, investigacióno conservación. Efectivamente, una normativa adaptada a las condiciones de ejecución de los proyectos de construcción y, tal vez, suficiente para regular las pautas de las excavaciones arqueológicas, no resulta eficaz para adoptar decisiones de conservación, y aunque no excluye la posibilidad de redactar un programa general en esta materia, el plazo de dos meses establecido para la resolución de cada expediente de obra hace imposible afrontar este programa con un conocimiento previo adecuado.

En definitiva, las decisiones de conservación en la Z.A.M.B., y de esta manera las posibilidades de musealización del sitio, se reconducen a la resolución en un tiempo tasado de la Delegación Provincial, asesorada por la Comisión Provincial de Patrimonio Histórico, sobre los distintos expedientes de edificación. Asimismo, cualquier decisión de conservar exige por supuesto la aplicación de unos recursos limitados, que siguen vías de asignación por completo ajenas a las instrucciones particulares, y además si se proyecta sobre áreas de uso lucrativo, significa también la indemnización económica a los propietarios afectados, bien directamente mediante la compra del suelo, o bien indirectamente otorgándoles compensaciones en otras áreas del sector (3). Sin duda, este contexto justifica suficientemente la dedicación del esfuerzo por conservar a las áreas de uso no lucrativo, como son los espacios dotacionales o las zonas verdes, donde en principio debemos suponer el desenvolvimiento de aprovechamientos públicos compatibles con la exposición de los restos arqueológicos, o donde como mínimo esperamos menores restricciones para la visita y contemplación de los mismos que en aquellas otras áreas de titularidad privada.

\section{SECUENCIA HISTÓRICA DE. MARROQUÍES BAJOS}

La secuencia de la zona arqueológica se inicia con una antigua ocupación de la margen derecha del arroyo de la Magdalena, recientemente detectada en el sector denominado S.U.N.P. n. ${ }^{\circ} 1$, que sus excavadores fechan en el Neolítico medio. El siguien-

(3) La Gerencia Municipal de Urbanismo del Ayuntamiento de Jaén ha optado por esta solución cuando a propuesta de la Delegación Provincial de Cultura, libera de uso lucrativo la manzana $\mathrm{C}$ y el borde oriental de la manzana $\mathrm{F}$ mediante una modificación puntual del Plan Parcial del sector R.P. n.1 4, que supone para los afectados un incremento de la edificabilidad (número de plantas) en otras parcelas de su propiedad, o directamente la cesión de parcelas de titularidad municipal. De esta manera, se ha conservado el área central del poblado prehistórico y su conexión con las zonas verdes proyectadas previamente para conseguir una cierta continuidad del futuro parque arqueológico. 
te momento se adscribe a la Edad del Cobre, cuando emerge un extenso poblado permanente durante la segunda mitad del tercer milenio, que en un trabajo anterior considerabamos una macro-aldea (Zafra y otros, 1999), un lugar situado a medio camino entre la comunidad parental y la ciudad que en este tiempo concentraba población y poder.

Esta llamada macro-aldea era un espacio circular definido por un foso que encierra una extensión aproximada de 113 ha, donde se distribuyen campos de cultivo, necrópolis y áreas de habitación. El centro del poblado se define por un nuevo foso de trayectoria circular, reforzado en su lado interior por una muralla de adobes, que discurre durante dos kilómetros cercando una extensión de 34 ha. Este núcleo interior se ordena a su vez por tres fosos concéntricos y en las respectivas coronas se encuentran calles, espacios abiertos y protomanzanas, amplias unidades domésticas que aglutinan cabañas, silos, pozos, hornos, etc. Las cabañas son indicativas de la variedad de recursos y soluciones arquitectónicas utilizadas, así se pueden encontrar parcialmente excavadas en el sustrato geológico, sustentadas con postes o construidas con adobes sobre un zócalo de piedras. La cronología absoluta de este establecimiento ha sido fijada en la segunda mitad del tercer milenio mediante fechaciones calibradas de muestras de carbón. Sin duda, las excavaciones no acabarán por recomponer una planimetría completa de este asentamiento, pero la documentación va a ser suficiente para revisar algunas ideas admitidas acerca de las formas del urbanismo primitivo, como también para volver a repensar sobre nuevas bases documentales el proceso de constitución de las llamadas formaciones sociales complejas.

Después del año 2000 a.n.e. (en fechaciones calibradas), se produce la dispersión de la población, y probablemente entonces sucede la primera ocupación de la parte alta de la ciudad histórica. Sólo se han registrado en la Z.A.M.B. varios enterramientos en cista de mampuestos adscritos a la Edad del Bronce pleno, que son las últimas evidencias prehistóricas hasta ahora documentadas. Una aparente interrupción de la ocupación que se mantiene durante un largo periodo de tiempo, hasta alcanzar los episodios finales de la cultura ibérica.

Hacia los siglos III-II a.n.e. se produce otra colonización de la Z.A.M.B., basada en una dispersión de pequeñas casas y en puntuales reutilizaciones de las antiguas construcciones subterráneas prehistóricas. Se trata de una economía agraria sustentada en los aprovechamientos de regadío, atomi- zada en minúsculas explotaciones, que pone en funcionamiento una red elemental de captación y distribución del agua (4). Coincidiendo con el cambio de era, se introducen instalaciones de nueva planta en esta ordenación agraria, como una almazara (5), un pozo y una cisterna (6), caracterizadas por modos de construir enteramente ajenos a la tradición ibérica, que por el contrario parece seguir vigente en los usos de la tierra y en la distribución del poblamiento. La ruptura de este modelo tardoibérico parece ocurrir en los años finales del siglo I d.n.e., cuando tal vez la constitución del municipio flavio de Aurgi, identificado con la actual ciudad de Jaén, motiva la implantación de formas más extensivas de explotación de la tierra, que reconocemos en una notable reducción de los sitios ocupados.

La etapa tardorromana, documentada en una extensa necrópolis localizada en la cabecera del futuro bulevar y en el sector U.A. n. ${ }^{\circ} 25$, sólo ha sido reconocida en algunos hallazgos arquitectónicos dispersos. Después, la ocupación de época emiral se concentra en las márgenes de los principales arroyos sobre una extensión aproximada de 20 ha (Castillo, 1997), donde aparecen casas aisladas rodeadas de campos irrigados.

Entre la segunda mitad del siglo IX y la primera del siglo X se produce un incremento importante de la población, entonces el asentamiento se dota de una rudimentaria urbanización, que entre otras cosas exige la reorganización de la red de distribución del agua, apareciendo una extensa huerta en las tierras bajas. Esta especial urbanización ha servido para definir un nuevo modelo de ciudad omeya, caracterizada por la coexistencia de varios núcleos separados espacial y funcionalmente (Salvatierra y otros, 1998). El establecimiento se destruye durante los enfrentamientos civiles de la segunda fitna, pero cierto tiempo después se vuelve a constatar la ocupación de algunas viviendas, que perduran durante los siglos XII y XIII.

(4) Se puede encontrar una primera revisión de esta etapa en la memoria de iniciación a la investigación de D. José Luis Serrano Peña, titulada Aurgi: el municipio romano desde la Arqueología urbana de Jaén, 1986-1995, leída el pasado año en la Universidad de Jaén.

(5) D. José Luis Serrano Peña ha anunciado la presentación de una comunicación sobre esta instalación en las I Jornadas Cordobesas de Arqueología Andaluza (Córdoba, 7 a 11 de noviembre de 2000), titulada Una almazara en Aurgi.

(6) Según información facilitada por D. Vicente Barba Colmenero se encuentra en preparación su memoria de iniciación a la investigación sobre estas construcciones, que será presentada durante el curso académico 2000/01 en la Universidad de Jaén, bajo el título Sistemas hidraúlicos de época romana en la zona arqueológica de Marroquíes Bajos, Jaén. 
La desarticulación de la Z.A.M.B. como un núcleo urbanizado ocurre con la conquista castellana de la ciudad de Jaén en el año 1246, precedida de un largo asedio, que motiva el abandono de casas, necrópolis, canales, norias y acequias. La repoblación cristiana presenta un impacto bastante menor, limitado a algunas edificaciones aisladas y a la construcción de un alfar. La recuperación del dinamismo de este ámbito agrario se data en el siglo XVI, cuando se levantan cortijos y caserías rodeados de olivares y huertas. Desde este siglo se observa la sucesión en la zona arqueológica de distintas coyunturas expansivas y regresivas de la economía agraria, pero en todo momento se mantienen los usos agrarios de la tierra hasta experimentar su colapso final con la urbanización de 1995.

\section{CONSERVAR PARA MOSTRAR}

Los trabajos de campo vienen recuperando exhaustivamente todos los elementos muebles hallados en las excavaciones, como también un extenso repertorio de muestras (sedimentos, fauna, polen, C-14, semillas, materiales de construcción...) procedente de toda la secuencia estratigráfica de la Z.A.M.B. Estas muestras y materiales pronto alcanzaron un importante volumen, y hacia el año 1996 los almacenes del Museo Provincial mostraban ya un cierta incapacidad para seguir recibiendo las entregas semanales, siendo entonces habilitado un antiguo silo de cereales como espacio para los depósitos de la Z.A.M.B. Este fondo de muestras y materiales va a seguir abierto a la investigación durante años, y sin duda los resultados que se obtengan unas veces complementarán, y otras modificarán, nuestro conocimiento de la zona arqueológica, aportando en este caso nuevos contenidos del discurso expositivo.

Asimismo, el proyecto básico de adecuación del área central redactado por el equipo interdisciplinar compuesto por Manuel Ibáñez Torrero, arquitecto, y Arturo Ruiz Rodríguez, arqueólogo, contempla la construcción en el lado meridional de la manzana C del R.P. n. ${ }^{\circ} 4$ de una plataforma de acceso al parque (ver sección en figura 4 ), apoyada exclusivamente en el límite de la calle, destinada entre otras funciones a albergar un uso cultural. Se puede imaginar en el futuro este espacio como contenedor de algunos muebles seleccionados y representativos de la secuencia histórica que ahora están siendo retirados de la zona arqueológica. En efecto, tanto la

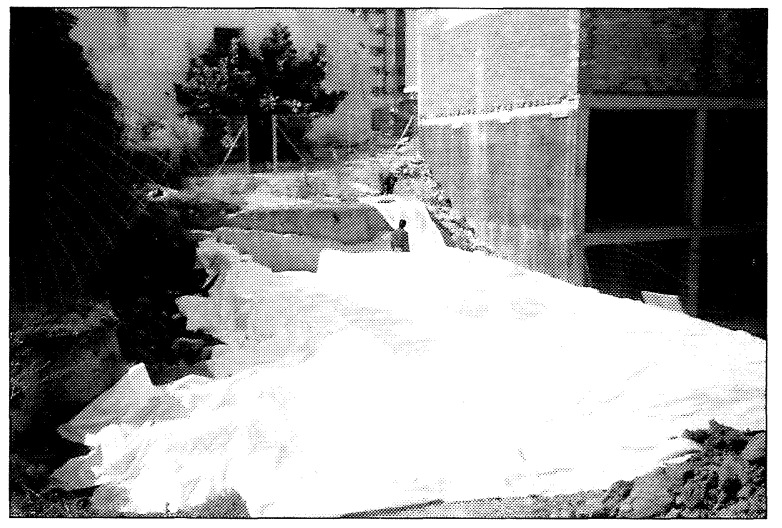

Lám. II. Trabajos de cubrición con malla geotextil de cisterna romana, borde oriental de manzana F (R.P. n. 1 4), Marroquíes Bajos (Jaén). Archivo de la Delegación Provincial de Cultura.

continuación de la investigación, como otras oportunidades que ahora apenas podemos valorar, van a condicionar la realización final del programa museográfico, por el momento enumeramos a continuación algunos de los espacios y elementos inmuebles conservados en estos años para construir el armazón de ese programa.

Se trata de un repertorio de elementos originales distribuidos en toda la Z.A.M.B. (Fig. 3), elegidos por su capacidad para ilustrar distintas maneras de habitar la zona arqueológica a través del tiempo, que forzosamente van a estar cruzados por el urbanismo y las formas arquitectónicas de la ciudad de nuestra época. La primera decisión que implica una conservación de cierta envergadura se realiza en la manzana E del sector U.A. n. ${ }^{\circ} 23$ durante 1996, donde la Sociedad Municipal de la Vivienda proyectaba la construcción de viviendas sociales. Se procede entonces al levantamiento controlado de una puerta de mampostería de la muralla prehistórica y otras construcciones en piedra cercanas para su posterior reubicación.

La localización de una cisterna (Lám. II) y un pozo de mampostería de época romana y de viviendas islámicas en el borde oriental de la manzana $\mathrm{F}$ del sector R.P. n. ${ }^{\circ}$ 4, durante las distintas excavaciones realizadas en 1997 en este lugar, determina otra decisión de conservación, esta vez encaminada al mantenimiento in situ de estos elementos. Esta decisión precipita una operación de mayor alcance para la conservación en la Z.A.M.B., la modificación del plan parcial del sector R.P. n. ${ }^{\circ} 4$, que elimina los usos lucrativos previstos inicialmente en este borde de la manzana F y en toda la manzana C. 
Este área constituiría el núcleo central del parque arqueológico sobre una extensión aproximada de 1 ha, coincidiendo con el centro del poblado prehistórico y donde se había observado una notable potencia de la secuencia estratigráfica de las siguientes fases de ocupación de la zona arqueológica.

La elección de esta zona, todavía hoy pendiente de excavación en su mayor parte, estuvo motivada por el simbolismo de su centralidad en el poblado prehistórico, la amplitud cronológica de la ocupación constatada en las calles adyacentes y, en particular, por la posibilidad de conexión con las zonas verdes proyectadas. De esta manera, el parque arqueológico vendría a contener además del centro indicado, una sección representativa de toda la Z.A.M.B. donde sería factible la conservación in situ de los restos arqueológicos, que discurre paralela a los espacios dotacionales donde se viene demandando una conservación preventiva de los depósitos antiguos.

Durante 1998 se emprende la primera intervención financiada por la Consejería de Cultura en el borde de la manzana $\mathrm{F}$ y en la calle adyacente, que tiene por objeto la primera adecuación de los restos conservados (Lám. II). También en esta intervención se decide, una vez explorada la calle inmediata, reinstalar el pozo de mampostería (Lám. III), preservando la distancia y la relación de axialidad que mantenía con la cisterna, pero consiguiendo un único plano de tránsito en el lado occidental del futuro parque. Este mismo año se levantan varias cistas de la Edad del Bronce para su traslado a otros puntos y, asimismo, se documentan otros enterramientos colectivos de la Edad del Cobre para su posterior recreación. Por último, las excavaciones previas a la construcción de una galería visitable en el lado occidental del bulevar pusieron de manifiesto la buena conservación de la muralla prehistórica en esta zona, y supusieron de hecho la interrupción de la obra que se venía ejecutando hasta encontrar soluciones de trazado alternativas, todavía hoy pendientes de aprobación por la Delegación de Cultura.

Las decisiones de conservación más relevantes del pasado año consistieron en el mantenimiento in situ de las construcciones hidráulicas de época prehistórica localizadas en la manzana $\mathrm{H}$ del sector R.P. n. ${ }^{\circ}$ 4, ocupando una extensión de $630 \mathrm{~m}^{2}$ entre los bloques de pisos, y de una almazara de época romana excavada en el extremo nororiental del S.U.N.P. n. ${ }^{\circ}$ 1. También se procede durante este año al levantamiento controlado de dos pozos de noria

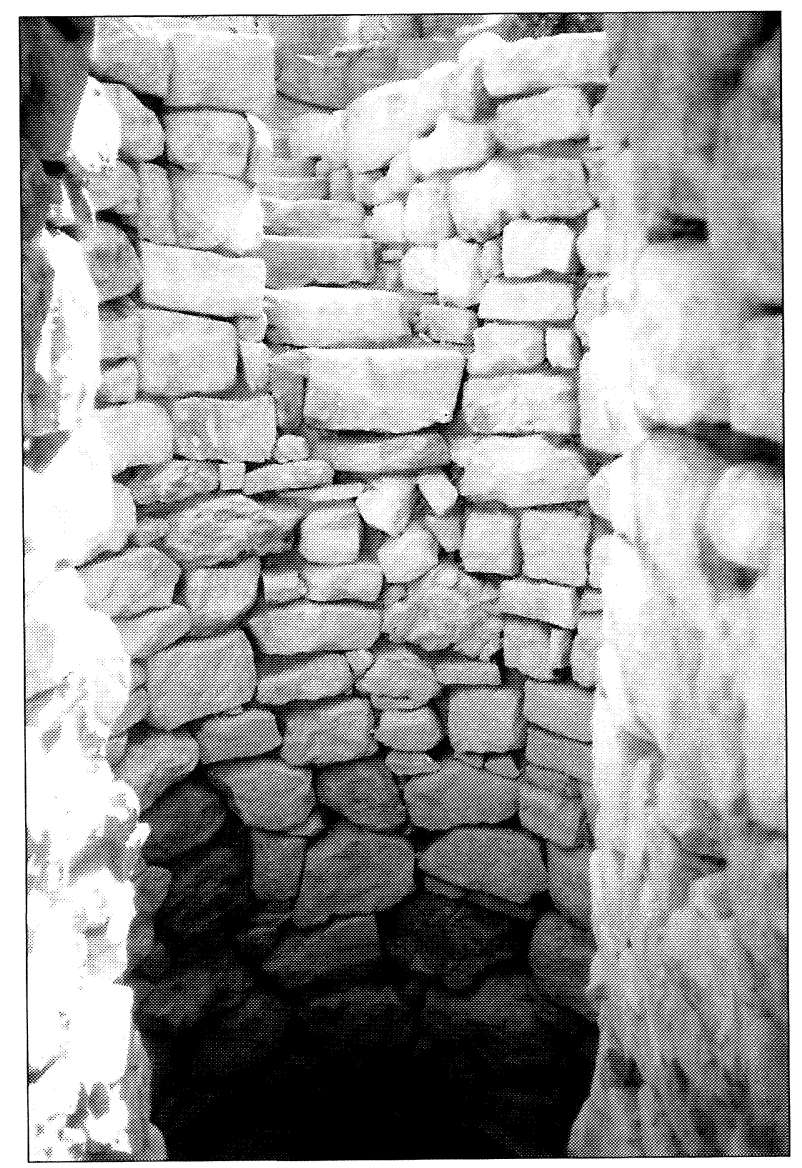

Lám. III. Pozo de época romana reinstalado en parque arqueológico, Marroquíes Bajos (Jaén). Archivo de la Delegación Provincial de Cultura.

en mampostería de época islámica y de una cabaña prehistórica construida con ladrillos.

Para terminar esta breve recapitulación, se debe señalar que este año se han iniciado los controles ambientales para la futura musealización de una tumba en cueva artificial y de otros espacios asociados de la Edad del Cobre, localizados en las excavaciones previas a la edificación de un colegio, que supusieron la modificación de este proyecto de obra. También en esta misma parcela se obtuvo el molde de varias cabañas de surco perimetral (Lám. I), que se destruirían con la edificación, para permitir posteriormente una fiel recreación de las mismas. Finalmente, después de realizar una primera campaña de sondeos estratigráficos en las zonas verdes del sector S.U.N.P. n. ${ }^{\circ} 1$ colindantes con las zonas verdes del R.P. n. ${ }^{\circ} 4$, se ha decidido solicitar a la empresa promotora excavaciones sistemáticas destinadas a la integración de los restos arqueológicos que

T. P., 57, n. $^{\circ} 2,2000$ 
pudieran aparecer en las mismas, constituyendo por tanto la primera realización del parque arqueológico que en un futuro cercano será visitable, aunque por una paradoja sea precisamente el área situada en el fondo de la zona musealizada.

\section{HORIZONTE DEL DISCURSO EXPOSITIVO}

\section{Disposiciones iniciales y destinatarios hipotéticos}

Se apuntaba antes que si bien existía un criterio general de conservación en la Z.A.M.B. establecido en las instrucciones particulares, como era la reserva de las zonas verdes previstas en la urbanización para la integración de los restos arqueológicos que pudieran aparecer en las mismas, todas las decisiones de conservación se adoptaron bajo unas circunstancias menos posibilistas y conciliadoras con el proyecto urbanístico. De acuerdo con el momento señalado en la normativa de protección, la Delegación Provincial de Cultura estaba obligada a decidir acerca de la conservación de un elemento en una precisa coyuntura, cuando se pronunciaba sobre la viabilidad de ejecutar cada proyecto de obra. Estas coyunturas sucesivas estuvieron delimitadas obviamente por los programas de edificación de los distintos sectores urbanísticos (U.A. n. ${ }^{\circ} 23$, R.P. n. ${ }^{\circ} 4$, S.U.N.P. $\mathrm{n}^{\circ} 1$...), que desde luego seguían un desarrollo ajeno a las necesidades de investigación y conocimiento del sitio, y por otro lado, por los resultados obtenidos en las excavaciones previas a cada edificación. Estas excavaciones aportaban una información limitada al contorno arbitrario de un solar particular, pero habiéndose sucedido de manera ininterrumpida durante cinco años, han servido también para proponer ciertas generalizaciones sobre el conjunto de la zona arqueológica, ciertamente provisionales y construidas ad hoc, pero que en cada momento aportaban el único argumento con valor comparativo capaz de sustentar las decisiones de conservación.

En definitiva, se dispone de un objeto expositivo todavía abierto, que ha sido el resultado de decisiones concretas de conservación adoptadas en el transcurso de varios años, cada vez más apegadas a una comprensión global de la zona arqueológica. No obstante, hasta el momento ninguna de estas decisiones ha estado determinada directamente por los requerimientos de la musealización del sitio y, aún en menor medida, se han contemplado las necesidades de los destinatarios finales de la conservación. Por el contrario, ahora se pretende devolver el protagonismo en las decisiones de musealización al público hipotético de la zona arqueológica, y una primera medida en este terreno consiste en identificar a los destinatarios posibles, porque sus disposiciones tienen implicaciones evidentes en la construcción del discurso expositivo y en los recursos utilizados.

Tal vez, no se deba esperar una satisfacción completa de las necesidades de todos los sectores del público reconocidos, sino un compromiso forzado entre demandas divergentes, dispuesto para ordenar prioridades y establecer criterios de actuación. Una indagación superficial en el comportamiento del público actual permite reconocer como mínimo tres modos de relación con la zona arqueológica, que reclaman formas específicas de ordenación espacial del proyecto museográfico. Un primer grupo se caracteriza por la exhaustividad de su acercamiento, demandando múltiples perspectivas y escalas en el reconocimiento de la zona arqueológica. Un segundo grupo persigue consolidar e ilustrar conocimientos adquiridos a través de itinerarios establecidos, desarrollando por tanto una experiencia limitada y dirigida a determinados segmentos de la zona arqueológica. Finalmente, quizás la mayoría de la población tiene una relación bastante casual con la zona arqueológica, porque se encuentra ante espacios que no ha buscado, que aparecen como simples intersecciones en sus líneas de tránsito, y por tanto este público va a tolerar los espacios musealizados sólo en la medida que éstos contribuyan a mejorar su percepción de la ciudad.

En un primer momento, la zona arqueológica interesa a un público altamente especializado, que sin duda era atraído por los variados resultados de intervenciones realizadas, o en curso de realización. La atención de este público estaba motivada por el carácter extensivo de las excavaciones en Marroquíes Bajos, que además de dejar al descubierto construcciones singulares como fosos, casas, murallas o cámaras funerarias, ante todo permitían conocer la organización de sectores amplios del poblado prehistórico o del barrio hispanomusulmán, donde se podían reconocer formas de organización del espacio en una escala verdaderamente desconocida hasta hoy, al menos en relación con otros sitios del mediodía peninsular que presentan una parecida secuencia cultural. Estas visitas fueron atendidas desde la misma Delegación Provincial de

T. P., 57, n. ${ }^{\circ} 2,2000$ 
Cultura, aunque también suponemos que en otras ocasiones fueron conducidas por los propios arqueólogos que dirigían cada una de las actividades.

El principal valor de la Z.A.M.B. para este público por tanto no se derivaba de un hallazgo excepcional, sino del volumen y la exhaustividad de las actividades de excavación practicadas, bien porque aportaban nuevos argumentos en distintas controversias académicas, o bien porque anunciaban nuevas direcciones de la investigación sobre la Prehistoria reciente o la época medieval. Estas expectativas de los visitantes explican que primero nos interrogaran sobre las pautas de la documentación de campo y, siempre en segundo lugar, sobre los criterios de conservación aplicados. Este público tiende a formalizar ideas propias acerca de la organización del espacio ocupado y resulta especialmente sensible a las variaciones ocurridas en estos esquemas en el transcurso del tiempo, comprendiendo cada elemento conservado como un evento dotado de significado dentro de un tiempo y un espacio característicos de la zona arqueológica. Sin duda, este público va a exigir, de una parte, autenticidad en los motivos de exposición, y por esta razón a menudo cuestionará las reintegraciones formales o la alteración del emplazamiento original, y de otra, perspectivas de observación amplias y diversas, que faciliten la conexión visual de los elementos conservados a través de una red de hitos de referencia.

Los escolares han sido hasta ahora el público más numeroso de la Z.A.M.B., y la visita programada con sus profesores ha consistido siempre en un itinerario parcial, que se trazaba de acuerdo con un tiempo limitado, sorteando las dificultades de acceso y pretendiendo mostrar la diversidad de evidencias conservadas. Este público procede mayoritariamente de centros de la propia ciudad de Jaén, donde el encuentro con Marroquíes Bajos completa la serie de tradicionales visitas culturales (Museo Provincial, catedral, castillo...), y se está ampliando a otras poblaciones cercanas (Mengíbar, Linares...). Los escolares reclaman con insistencia puentes formales, argumentales y materiales entre las explicaciones recibidas y las evidencias observadas.

Las demandas de este sector del público parecen justamente enfrentadas a aquellas apuntadas para el anterior. Si antes se subrayaba la originalidad de Marroquíes Bajos en varios discursos posibles, ahora las evidencias conservadas sólo son instrumentalizadas para probar la veracidad de una serie de conocimientos adquiridos previamente, relacionados casi siempre con la secuencia histórico-cul- tural de la región, aunque también en ocasiones con temas medioambientales o urbanísticos, como los procesos de erosión y transporte, el aprovechamiento del agua, o el crecimiento de la ciudad. Este enfoque requiere enfatizar la correspondencia entre los vestigios conservados y determinadas propuestas reconstructivas. Así, por ejemplo, hemos podido comprobar la dificultad de la mayoría de los escolares para percibir una sencilla cabaña de postes, cuando las huellas del perímetro y el hogar central resultaban tan evidentes para sus excavadores. Un medio improvisado, que hemos utilizado a menudo para paliar esta dificultad, consiste en distribuir a algunos escolares ocupando la posición de cada uno de los postes, e introducir al resto del grupo dentro de este espacio respetando ciertas pautas básicas de circulación. Sólo de esta manera empiezan a comprender la relación entre el plano descubierto y el volumen desaparecido, y con frecuencia descubren que el espacio resultante sorprendentemente tiene la extensión suficiente para acoger múltiples actividades domésticas. Sin duda, la restitución material constituye un recurso idóneo para una presentación pedagógica de las más débiles construcciones recuperadas por la excavación, además de contribuir a su conservación cuando se han alterado las condiciones iniciales que aseguraron su existencia durante siglos.

En algunas fechas especiales como la convocatoria anual de las Jornadas Europeas del Patrimonio Histórico, o con motivo de solicitudes formuladas por asociaciones de vecinos o por algún grupo político municipal, la Z.A.M.B. se ha abierto también a los ciudadanos de Jaén mediante visitas organizadas, siguiendo las mismas pautas señaladas para los grupos anteriores. Sin embargo, la relación de la mayor parte de este sector del público con la zona arqueológica ocurre accidentalmente, oscilando la respuesta común ante las evidencias arqueológicas entre la curiosidad y el desconcierto. Definitivamente, la zona arqueológica para este grupo apenas puede competir con el interés suscitado por las nuevas viviendas en construcción.

Finalmente, las disposiciones de los distintos sectores del público, que brevemente hemos esbozado, se deben completar con un público todavía ausente, que podemos considerar estrechamente relacionado con la oferta turística de la ciudad de Jaén, hasta ahora centrada en la catedral, el castillo de Santa Catalina, las calles de la ciudad histórica y los distintos museos. La ciudad de Jaén se contempla normalmente como un destino secundario 
de este público, pues la oferta turística en el marco provincial se encuentra dirigida hacia los parques naturales (en particular, Cazorla, Segura y las Villas) y la monumentalidad del Renacimiento (Baeza y Úbeda), bajo el lema Jaén, paraíso interior que promueve la Diputación Provincial. La Z.A.M.B. musealizada significaría simplemente un centro de interés secundario en la ciudad de Jaén, que a su vez constituye un destino secundario del turismo en la provincia.

\section{Nuevos contextos, nuevos significados}

Si obviamos la posibilidad de adquirir conocimiento o lograr nuevas aportaciones, cualquier actividad arqueológica se caracteriza ante todo por introducir una radical dislocación en un contexto preexistente. Los objetos y las evidencias arqueológicas son privados de su significado anterior, y sólo mediante la documentación obtenida alguien puede jactarse provisionalmente de su capacidad para recomponer cada una de las interrelaciones que son necesarias en la reconstrucción del sentido o sentidos originales. Esta situación a menudo impide reconocer la capacidad creadora de significados que tiene la actividad arqueológica, bien porque inserta materiales y muestras en unas nuevas relaciones espaciales, a veces ocultas en la oscuridad de los almacenes de los museos y otras veces desplegadas a la luz del día, o bien porque atribuye un significado novedoso a algo ya existente y accesible para el público.

Despreciada oficialmente la posibilidad de aprehender un significado en un objeto aislado, que erróneamente se confunde con una valoración exclusivamente estética de su dimensión artística, las claves de la exposición arqueológica se concentran en las asociaciones descubiertas entre los objetos y en los significados atribuidos a las mismas. Los objetos cobran sentido en la conformación de una trama de relaciones espaciales, que forzosamente va a ocurrir en nuestro presente, ya tratemos de las asociaciones más sencillas y recurrentes (punta de flecha y astil, flecha y arco...), a las más complejas relaciones que caracterizan una sociedad o un paisaje. En todo caso, el recorrido de la simplicidad a la complejidad resulta siempre insuficiente en alguna escala, porque siempre va a existir un límite en la recreación expositiva de la trama de relaciones espaciales, una fisura insalvable entre la situación original de los objetos y la posición actual de los mismos inducida por la actividad arqueológica, que introduce un obstáculo para la comprensión de los vestigios por el público. Esta situación nos obliga a actuar como mediadores conscientes en un proceso de comunicación, donde como punto de partida no podemos excluir ningún recurso, ni ningún mensaje posible, del discurso expositivo, pues la eficacia de este proceso constituye el principal objetivo de cualquier programa de musealización.

\section{Escalas y recursos de (re)presentación}

Los paisajes destruidos y el mismo procedimiento arqueológico de recuperación de la información necesitanintermediaciones cálidas para participar realmente en un proceso de comunicación, constituidas por todo aquello que se construye para reinsertar en nuestro tiempo una serie de objetos desplazados de su contexto original. Estos instrumentos dispuestos con el diseño del parque arqueológico persiguen materializar formas nuevas de apropiación y contemplación del espacio, como un requerimiento previo al enunciado de cualquier mensaje.

Si la operación anterior tiene un cierto éxito, se pueden empezar a discutir los contenidos del discurso expositivo, que en el caso de la Z.A.M.B. nos proponemos reconducir a dos escalas principales, espacio local y espacio doméstico. Las investigaciones realizan sus reconstrucciones en alguna de estas escalas, y por tanto se pueden seguir utilizando como motivo de la (re)presentación pública de las mismas. La primera escala pretende facilitar una lectura de los sucesivos momentos de construcción del paisaje, recurriendo a la noción de iconema propuesta por Turri (2000: 21), como una unidad elemental de percepción o imagen que representa el todo. Reconociendo los indicadores fundamentales del paisaje de una época (topografía, vegetación o construcciones), se trataría de recomponer islas de sentido que actuaran como signos de un determinado iconema.

La segunda escala de representación del discurso expositivo se centra en el descubrimiento arqueológico inmediato, donde encontramos relevante el concepto de cronotopo como una estructura de tiempo espacializado (Clifford, 1999: 38), una escena que sintetiza un tiempo y un espacio característicos de una cultura. Los cronotopos vendrían a completar los restos fragmentarios en el tiempo y en el espacio de distintos elementos recuperados por la excavación en puntos aislados de la zona ar-

T. P., 57, n. ${ }^{\circ} 2,2000$ 
queológica, actuando como referencias a distintos modos de vida.

\section{CONSTRUCCIÓN URBANA Y RECONSTRUCCIÓN ARQUEOLÓGICA}

\section{Adecuación de lugares y sitios}

La diversidad de formas de conservación ensayadas en la zona arqueológica, comprendidas entre dos situaciones extremas como son el mantenimiento en su emplazamiento original de las construcciones recuperadas por la excavación o la simple documentación gráfica de las mismas, haría posible también una notable diversidad de formas de integración de vestigios concretos y de presentación pública de la información obtenida. No obstante, la coherencia del discurso expositivo demanda el establecimiento de una serie de principios uniformadores. Estos principios deben conciliar dos necesidades aparentemente contradictorias, de una parte fomentar la familiaridad del público con unos mismos recursos expositivos, que premian su disposición a aprender en el transcurso del itinerario, y de otra, subrayar el carácter único y exclusivo de cada sitio para contrarrestar el cansancio provocado por la reiteración de formas, motivos y centros de atención.

Los principios de adecuación de los lugares y los sitios también deben ser examinados en varias escalas. Así, el principio uniformador más evidente se debe encontrar tanto en los indicadores, señales, soportes y demás mobiliario incorporado a los espacios expositivos, como en los temas, estructura y lenguaje de las narraciones textuales imprescindibles. Se debe perseguir en el primer aspecto una neta diferenciación formal con el mobiliario urbano circundante, de manera que estos elementos sirvan como hitos de referencia para el público, y su diseño debe procurar asimismo una cierta receptividad, que normalmente está ausente en la calle como ámbito exclusivo de tránsito. Por el contrario, se considera beneficiosa a media y larga distancia la incorporación de las referencias a la zona arqueológica en la misma señalización urbana existente (accesos, paradas de autobuses, puntos de información...), porque en esta escala se pretende enfatizar la posición de los espacios expositivos como una parte indiferenciada, permanente y cotidiana de la ciudad, destinada a conformar un aspecto inseparable de su propia identidad.

\section{Articulación de los espacios}

La ordenación urbanística de la zona arqueológica había sido concebida para resolver la única realidad existente en los inicios de la década de 1990, el borde septentrional de la ciudad consolidada, bloqueado durante años por la posición de la estación de ferrocarril, y su conexión con la carretera de Madrid y el polígono industrial. La idoneidad de las soluciones adoptadas viene siendo objeto de controversia, aunque alguna de ellas como la prolongación del Paseo de la Estación, que ha sido el principal eje de crecimiento de la ciudad en este siglo, encuentra una unanimidad casi completa. Esta ordenación ha sido modificada puntualmente para liberar de uso residencial-lucrativo la manzana $\mathrm{C}$ y el borde oriental de la F del sector R.P. $n .^{\circ} 4$, donde se contemplaba la redacción posterior de otra figura de planeamiento (estudio de detalle o plan especial). Este desarrollo pósterior del planeamiento debe ordenar la distribución de las zonas verdes previstas inicialmente, los nuevos espacios dotacionales creados con la modificación del plan parcial y las calles circundantes, para armonizar la futura realidad del parque arqueológico con su entorno urbano. No obstante, no existe todavía ni siquiera un avance de este documento de ordenación, que resultaría fundamental para evitar el aislamiento visual de los accesos e itinerarios del parque dentro de la ciudad.

\section{PERSPECTIVAS}

La coyuntura actual de la Z.A.M.B. presenta tres vertientes que van a condicionar el tiempo de ejecución y la materialización final del proyecto museográfico, relacionadas con la conclusión de las investigaciones urgentes, la progresiva ocupación de las viviendas y, sin ninguna duda, la cuantía y regularidad de las inversiones públicas.

La financiación privada de las excavaciones prácticamente ha acabado en los sectores R.P. n. ${ }^{\circ} 4$ y U.A. n. ${ }^{\circ} 23$, donde se ha documentado la mayor intensidad de la estratigrafía arqueológica, y aunque va a continuar todavía durante otros cinco o seis años en el S.U.N.P. n. ${ }^{\circ} 1$, no se espera que en este sector alcance el mismo volumen, tanto por la realización de una investigación previa a la urbanización bastante exhaustiva, que en ocasiones ha exigido la modificación del proyecto para aminorar las afecciones, como por las mismas características de la edificación en este sector (viviendas unifamilia- 
res). Esta circunstancia nos lleva a prever escasas novedades en los próximos años en los espacios y construcciones susceptibles de musealización fuera del parque central.

La segunda vertiente señalada, la ocupación por los vecinos de las nuevas viviendas, se contempla como una oportunidad para agilizar tanto las obras de urbanización todavía pendientes, como la construcción de los espacios dotacionales, incluyendo el bulevar y el parque arqueológico, que se han presentado como reclamo publicitario por las sociedades promotoras. Los logros del movimiento vecinal en otro área de reciente crecimiento de la ciudad de Jaén, el barrio de Las Fuentezuelas, constituyen en este sentido una experiencia alentadora.

Por último, el proyecto básico de adecuación del área central de la Z.A.M.B. (Ruiz Rodríguez e Ibáñez Torrero, 1999) ha cuantificado las necesidades de inversión pública y establecido un orden prioridades de las actuaciones imprescindible. El primer objetivo se concreta en la excavación arqueológica de la manzana $\mathrm{C}$ y otras áreas adyacentes, que según el proyecto será planteada haciendo compatibles los trabajos de documentación con la visita pública a los mismos. El desarrollo de este proyecto de investigación ha sido objeto de un convenio, suscrito recientemente entre la Consejería de Cultura y el Centro Andaluz de Arqueología Ibérica de la Universidad de Jaén, que tiene un periodo de vigencia de cinco años.

\section{BIBLIOGRAFÍA}

CAstillo, J.C. (1997): "Las primeras fases de ocupación islámica de Marroquíes Bajos, Jaén”. Arqueología y Territorio Medieval, 4: 81-102.
Clifford, J. (1999): Itinerarios transculturales. Gedisa. Barcelona.

Fernández Alba, A. (1990): Los Axiomas del Crepúsculo: Ética y Estética de la última Arquitectura. Hermann Blume. Madrid.

HorkheImer, M. y Adorno, Th.W. (1999): Dialéctica de la Ilustración. Círculo de Lectores. Barcelona.

Hornos, F.; Zafra de la Torre, N. y CASTRo, M. (1998): "La gestión de una zona arqueológica urbana: La experiencia de investigación aplicada en Marroquíes Bajos (Jaén)". Boletín del Instituto Andaluz del Patrimonio Histórico, 22: 82-91.

GonZÁLEZ MÉNDEZ, M. (1997): "Landscape Archaeology as a Narrative for Designing Archaeological Parks". En F. Criado y C. Parcero: Landscape, Archaeology, Heritage. Tapa 2. Santiago de Compostela: 47-51.

Ruiz Rodríguez, A.; Zafra de la Torre, N.; Hornos, F. y CAstro, M. (1999): "El seguimiento de la intervención arqueológica: El caso de Marroquíes Bajos en Jaén". Actas del XXV Congreso Nacional de Arqueología (Valencia, 1999). Valencia: 407-419.

Salvatierra, V.; Serrano, J.L. y Pérez, M. a C. (1998): "La formación de la ciudad en al-Andalus: Elementos para una nueva propuesta". En P. Cressier y M. García Arenal (ed.): La genèse de la ville islamique en al-Andalus et au Maghreb occidental. Casa de VelázquezCSIC. Madrid: 185-206.

TURri, E. (2000): "La lettura del paesaggio". En VV.AA.: El paisaje mediterráneo: Sistema de información paisajístico. Consejería de Obras Públicas de la Junta de Andalucía. Sevilla: 12-32.

ZAFRA DE LA ToRre, N. (1996): "Hacia una metodología para el estudio del patrimonio arqueológico". En M. a A. Querol y T. Chapa (ed.): Homenaje al prof. Fernández Miranda, Complutum Extra 6 (II): 225-239.

Zafra de la Torre, N.; CAstro, M. y Hornos, F. (1999): "Una macro-aldea en el origen del modo de vida campesino: Marroquíes Bajos (Jaén) c. 2500-2000 cal. ANE”. Trabajos de Prehistoria, 56, 1: 77-102.

T.P., 57, n. ${ }^{\circ} 2,2000$ 